\title{
A Rare Case Report of Invasive Ocular Surface Squamous Neoplasm of Conjunctiva
}

\author{
Noopur Subhash Patil, Shivraj N. Kanthikar*, Prashant B. Chege and Sheela N. Kulkarni \\ Dept of Pathology, MIMSR Medical College, Latur (MH) -India
}

\begin{abstract}
Ocular surface neoplasm(OSSN) represent a rare but broad spectrum of disease, including mild dysplasia on one end of the spectrum and invasive Squamous cell carcinoma(SCC) on the other. Thus, the diagnosis completely depends on histopathological examination of the lesion. The incidence of ocular surface neoplasia is strongly associated with factors like solar ultraviolet radiation, HIV and human papilloma virus(HPV) infections. Most lesions occur at the limbus within the interpalpebral fissure particularly the nasal side. Their importance lies in the fact that they mimic benign lesions like pterygium or even chronic conjunctivitis and thus can be misinterpreted and inadequately treated. Red eye and ocular irritation are the most common presenting symptoms. No tumor related deaths or metastasis are generally seen. Surgery with intra-operative control of surgical margins and adjunctive chemotherapy, immunotherapy and cryotherapy result in good tumor control rates, with promising results in aggressive, recurrent and large tumors.
\end{abstract}

\section{Keywords: Ocular Surface Neoplasia; HPV; Squamous Cell Carcinoma;}

\section{Introduction}

Ocular surface neoplasia (OSSN) comprises of a spectrum of tumors that affects the ocular surface ranging histologically from intraepithelial neoplasia to different grades of invasive squamous cell carcinoma. Early lesions of varying size occur at the area of transition between the cornea and conjunctiva i.e. the limbus. Advanced stages may involve eyelids and invade orbit. But, more surprisingly OSSN usually affects only one eye. ${ }^{[1]}$

The term ocular surface squamous neoplasia was coined by Lee and Hirst which has three tier grading system including benign on one end and invasive carcinoma on the other:

\begin{tabular}{|l|l|}
\hline 1)Benign & 1) Papilloma \\
dysplasia & $\begin{array}{l}\text { 2) Pseudoepitheliomatous hyperplasia } \\
\text { 3) Benign hereditary intraepithelial } \\
\text { dyskeratosis }\end{array}$ \\
\hline 2)Preinvasive & $\begin{array}{l}\text { 1) Conjunctival/corneal carcinoma in } \\
\text { Situ (aka Bowen's disease) }\end{array}$ \\
\hline $\begin{array}{l}\text { 3)Invasive } \\
\text { OSSN }\end{array}$ & $\begin{array}{l}\text { 1) Squamous cell carcinoma } \\
\text { 2) Rare variants like Mucoepidermoid } \\
\text { carcinoma, Papillary, Adenomatoid, } \\
\text { Sarcomatoid. }\end{array}$ \\
\hline
\end{tabular}

The average incidence of OSSN of conjunctiva and cornea varies between 0.13 cases in 100,000 to 3.5 cases in 100,000 population. ${ }^{[2]}$

The etiology of the conjunctival cancers appears to be multifactorial, including smoking, sun exposure, latitude, history of pterygium, both human papilloma virus and HIV infections. ${ }^{[3]}$

Ultraviolet B radiation has been implicated in its pathophysiology with various mutations in $\mathrm{p} 53$ leading to the development of Squamous cell carcinoma.

Clinically tumors arise in the interpalpebral area at the nasal sector, grossly being either nodular, gelatinous, flat superficial leukoplakic or diffusely infiltrating. ${ }^{[4]}$

Histopathological evaluation is essential for the definitive diagnosis and also to differentiate the three lesions in the wide spectrum of OSSN.

Recently, new Immunohistochemistry detectable markers p53 protein, bcl-2 protein, MIB-1 are being used as prognostic markers. The interplay of mutations in p53, absent bcl-2 and increased elaboration of MIB-1 are said to contribute to the progression of this neoplasm. ${ }^{[5]}$

We report a case of OSSN in a 60 years old female who was misdiagnosed as Pterygium, and later operated for the same.

\section{Case Report}

A 60 years old female patient presented with the chief complaint of mass in her Right eye for the past 6months, progressively growing in size, associated with redness, watering, irritation and mild pain. She was on topical antibiotics and steroids prescribed by a local doctor. The patient had no history of trauma but was operated for a cataract in the same eye 10years back. General and 
systemic examination: Unremarkable, Uncorrected visual acuity in her right eye was $6 / 18$.

On local examination of right eye, a greyish red irregular lesion of size $2 \times 1 \mathrm{~cm}$ was present at the limbus, extending from medial canthus to pupil (Figure 1) with engorged feeder vessels at the base of the lesion.

Blood routine and serological investigations were negative. After taking informed written consent from the patient, surgical excision was done and specimen was sent to Histopathology department.

Histopathology showed a tumor (Figure 2,3) arranged in islands, nests and singly scattered. Individual tumor cells are round to polygonal, with round hyperchromatic nuclei, prominent 1-2 nucleoli and abundant eosinophilic

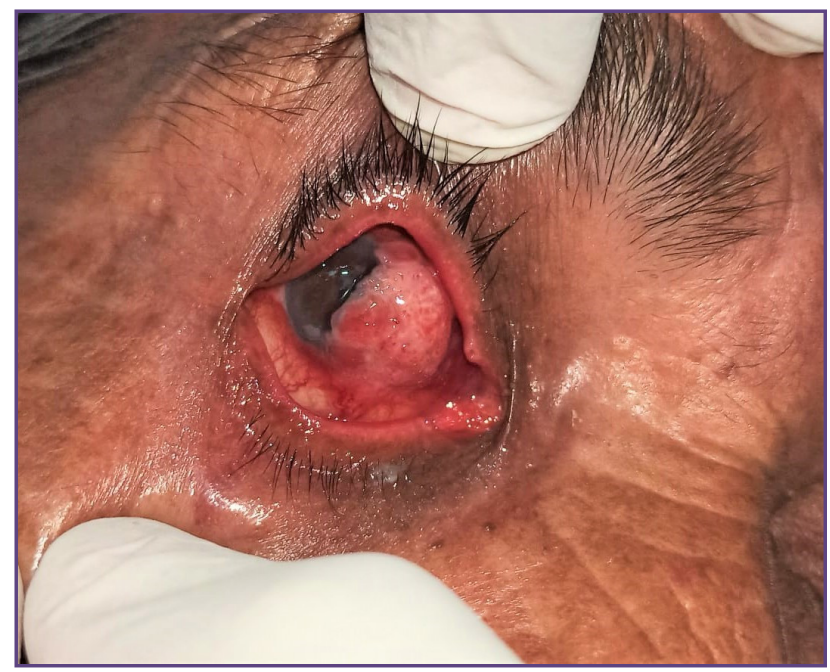

Fig. 1: Pre-operative picture of the lesion.

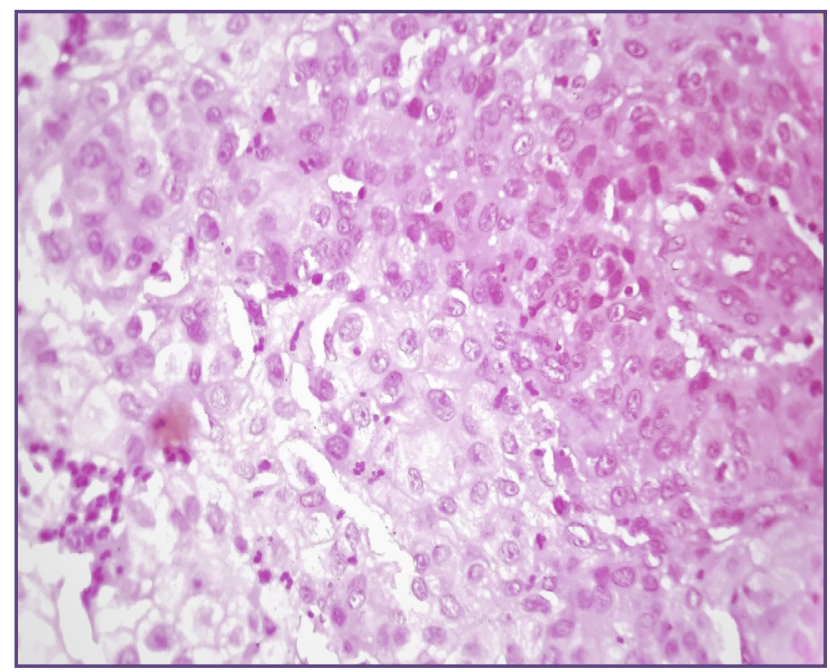

Fig. 3: Malignant squamous cells (H\&E, 40X View). cytoplasm. At places prominent keratin pearl formation noted (Figure 4).

Sections from adjacent squamous epithelium showed moderate dysplastic changes (Figure 5).

A final diagnosis of Invasive Well to Moderately differentiated Squamous cell carcinoma was made.

Patient was reviewed regularly. Postop period showed no recurrences (Figure 6).

\section{Discussion}

The average incidence of OSSN of conjunctiva and cornea was found to be $0.13 / 1$ lac in tribal groups in Uganda by Templeton in a study in 1967, and 1.9/1 lac population per year in the Brisbane metropolitan area of Australia by Lee

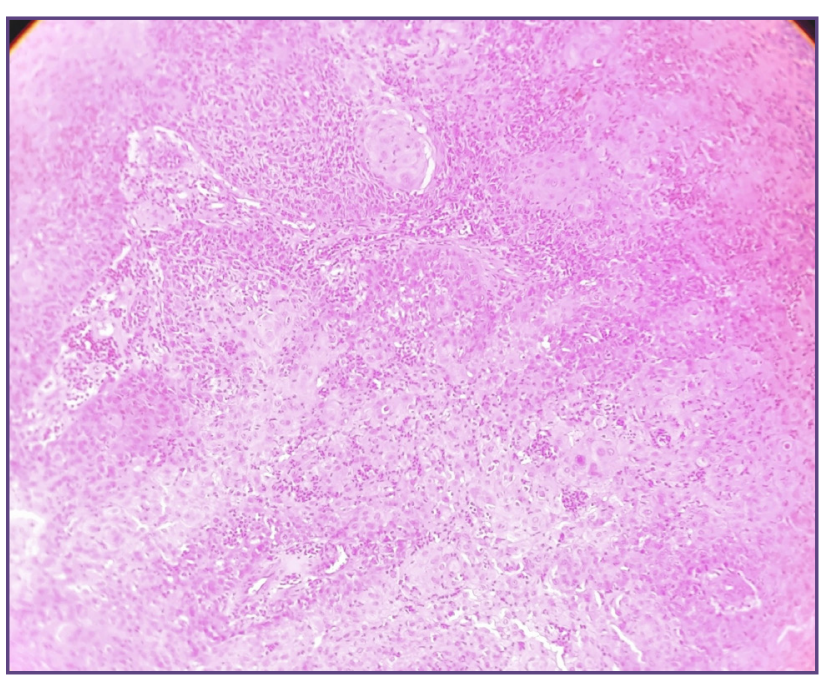

Fig. 2: Tumor islands and nests (H\&E, 10X View).

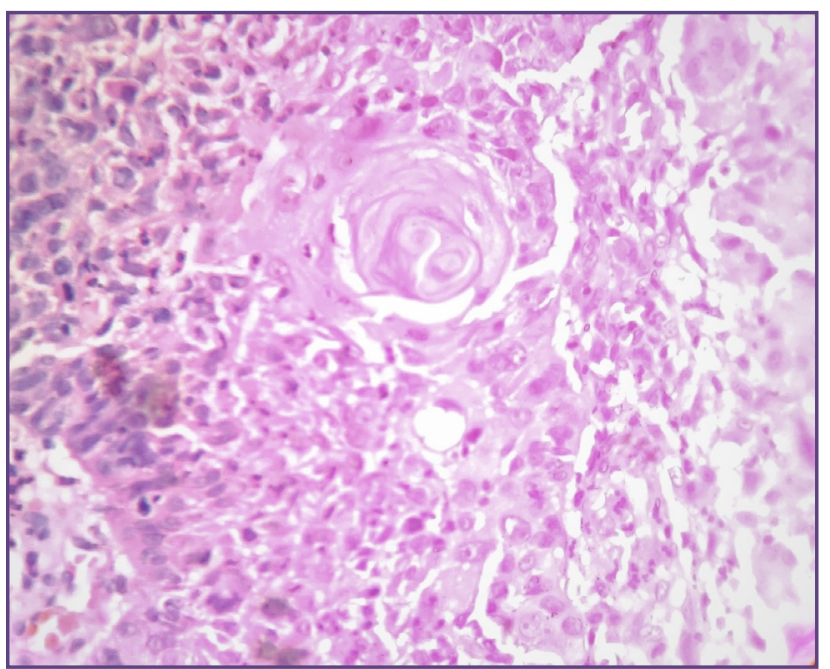

Fig. 4: Prominent keratin pearl formation (H\&E, 40x View) 


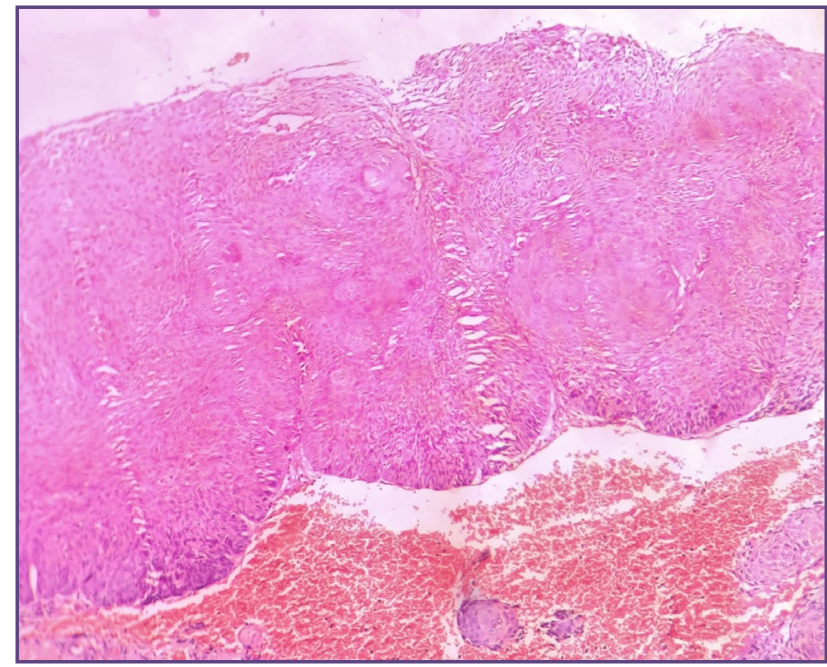

Fig. 5: Dysplastic epithelia (H\&E, 40X View).

in 1992. In a recent study published in 2012, an incidence of 37.3 per 10 lacs was reported for all eye cancers and 8.4 per 10 lacs for SCC. The incidence of OSSN has geographical variations, more common in regions closer to the equator and countries where excessive exposure to sunlight is seen. Males are more affected than females, with average age of presentation between 60-70years. Also seen in people with xeroderma pigmentosum and HIV, and thus all people with OSSN must be screened for HIV. ${ }^{[6]}$

A wide range of etiological factors have been implicated in the development of OSSN, key events include DNA damage which forms the basis of the carcinogenesis, with mutations in the DNA nucleotide sequence which can lead to genomic instability and stem cell dysfunction and is mostly caused by UVB radiations explained next. ${ }^{[1]}$

UVB radiation in exposed sunlight acts as a major etiological factor in the pathology of OSSN, as in our case as the patient was a farmer by profession. ${ }^{[6]}$ It causes direct DNA damage to form CPDs which distort the DNA structure and block DNA synthesis. Specific dimer CC TT transformation occurring at the P53 gene is the signature UVB mutation seen. ${ }^{[1]}$

The human papilloma virus a member of the oncogenic virus community is related to development of papilloma, dysplasia and squamous cell carcinoma in the various sites of the body. Out of all the various types, HPV 6 and 11 are associated with papillomatous proliferative lesions \& HPV 16 and 18 are linked to malignant progression. ${ }^{[7]}$ Integration of the virus within the host DNA is the critical step in the malignant transformation of the cell. ${ }^{[8]}$

Various mechanisms like Apoptosis and an active immune surveillance can correct carcinogen induced DNA damage

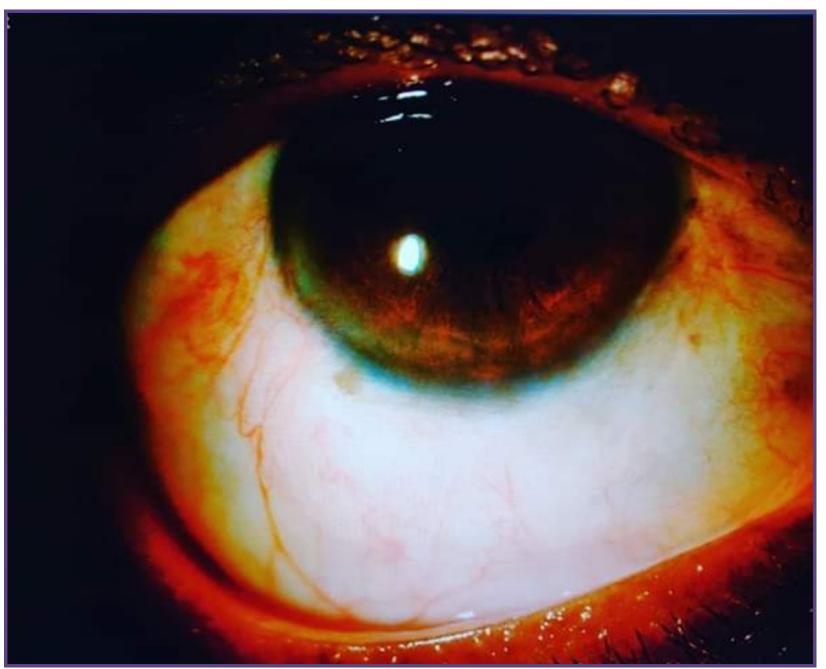

Fig. 6: 6 months post-op, with no recurrence of the tumor.

and eliminate such damaged cells from the healthy tissue. The pathway responsible for repairing the CPDS is the NER pathway and hampering of this pathway leads to accumulation of these Pyrimidine dimers. ${ }^{[1]}$

p53 is the guardian of the genome and Mutation or inactivation of p53 lead to genomic instability and increased proliferative activity of cell. ${ }^{[1]}$

A 12-fold excess overall risk for SCC in patients with HIV has been noted. ${ }^{[9]}$

The nutritional function of Vit. A is well known, and deficiency of this essential vitamin leads to squamous metaplasia of conjunctiva. Other effects are break in integrity of surface epithelium, micro-abrasions and thus allowing entry of HPV virus, dysregulation of stem cells due to loss of a differentiated phenotype leading to formation of cancer stem cells. ${ }^{[1]}$

Clinically, the patient presents with a mass at the limbus, tuft of blood vessels in the interpalpebral area, with bulbar conjunctiva being most commonly involved. ${ }^{[10]}$

Grossly three types of lesions maybe seen Gelatinous (Papilliform or Leukoplakic) - Most common form well circumscribed sessile papillomatous lesion with dilated conjunctival vessels, Nodular - Elevated mulberry like masses and Diffuse - Poorly demarcated with a radial growth pattern. ${ }^{[6]}$

The various diagnostic modalities are Exfoliative cytology in which the desquamated corneal and conjunctival cells can be studied with exfoliative cytology using cytobrush and or platinum spatula and/or impression cytology using cellulose acetate paper. 
The most important is Histopathological examination in which the excised tissue is placed on filter paper, placed in $10 \%$ buffered formalin with margins submitted in separate cassettes with appropriate labelling. ${ }^{[8]}$ OSSN is classified as either pre invasive or invasive. The pre invasive depends on the extent of dysplasia in the epithelium. It is Mild: CIN1, up to lower one third; Moderate: CIN2, involves up to middle third; Severe: CIN3, involves full thickness, known as carcinoma in situ.

Invasive carcinoma is said when the basement membrane is breached, and stroma is infiltrated.

Variant of invasive squamous cell carcinoma include: Sarcomatoid carcinoma, Mucoepidermoid carcinoma, Papillary SCC and Adenoid SCC. ${ }^{[8]}$

Additional modalities include: Confocal microscopy which is a non-invasive diagnostic modality for initial diagnosis, recurrences, treatment monitoring and response evaluation and Anterior segment optical coherence tomography (SOCT) which is also a non-invasive modality for assessing the epithelial thickness and reflectivity of the epithelium.

Differential diagnosis is Pterygium, Pinguecula, Papilloma, Keratoacanthoma, Amelanotic nevus, Malignant melanoma, Dermoid, Lymphoma. ${ }^{[8]}$

Treatment can be in the form of Complete wide local excision with adequate borders using a No-touch surgical technique. Rose Bengal/Lissamine green stain is used to delineate margins of the lesion. Chemotherapy using drugs like Mitomycin-C (0.02\%) and 5-FU (1\%) can be used for recurrences. Immunotherapy using IFNa2b can be used for wider and extensive OSSN.

Positive surgical margins play the most important role in tumor recurrence. Overall prognosis is good, as it is a lowgrade malignancy ${ }_{[}^{[6]}$

\section{Conclusion}

Histopathology is gold standard for diagnosing various spectra of OSSN. It is important to know the exact pathogenesis of OSSN and thus additional investigations are needed. A follow-up for recurrence is must. Adjunctive modalities must be used for large, unresectable and recurrent tumors.

\section{Funding}

None

\section{Competing Interests}

None

\section{Reference}

1. Gichuhi S, Ohnuma S, Sagoo M, Burton M. Pathophysiology of ocular surface squamous neoplasia. Experimental Eye Research. 2014; 129:172-182

2. Patel S, Pokharel B, Shah A, Goda M, Thapa S. ClinicoPathological Study of Ocular Surface Squamous Neoplasia in a Tertiary Care Centre of Western Region of Nepal. Journal of Universal College of Medical Sciences. 2019;7(1):9-13.

3. Asadi-Amoli F, Ghanadan A. Survey of 274 patients with conjunctival neoplastic lesions in Farabi Eye Hospital, Tehran 2006-2012. Journal of Current Ophthalmology. 2015;27(1-2):37-40.

4. Tunc M, Char D, Crawford B, Miller T. Intraepithelial and invasive squamous cell carcinoma of the conjunctiva: analysis of 60 cases. British Journal of Ophthalmology. 1999;83(1):98-103.

5. Viswamithra P, Bhaskara N. Ocular surface squamous neoplasia. Journal of Dr NTR University of Health Sciences. 2014;3(3):185.

6. Sethi H.S, Naik M, Joshi M, Gupta V S. Ocular surface squamous neoplasia (OSSN). DOS Times- Vol. 20, No. 6 December,2014:65-70.

7. Saegusa M, Takano Y, Hashimura M, Okayasu I, Shiga J. HPV type 16 in conjunctival and junctional papilloma, dysplasia, and squamous cell carcinoma. Journal of Clinical Pathology. 1995;48(12):1106-1110.

8. Mittal R, Rath S, Vemuganti G. Ocular surface squamous neoplasia - Review of etio-pathogenesis and an update on clinico-pathological diagnosis. Saudi Journal of Ophthalmology. 2013;27(3)

9. Guech-Ongey M, Engels E, Goedert J, Biggar R, Mbulaiteye S. Elevated risk for squamous cell carcinoma of the conjunctiva among adults with AIDS in the United States. International Journal of Cancer. 2008;122(11):2590-2593.

10. Templeton A. Tumors of the eye and adnexa in Africans of Uganda. Cancer. 1967;20(10):1689-1698.

*Corresponding author:

Dr. Shivraj N. Kanthikar, Associate Professor, First floor, Dept. of Pathology, MIMSR medical college, Vishwanathpuram, Latur-413512 INDIA

Phone: +919764777213

Email: skanthikar@gmail.com

Date of Submission : 02/04/2020

Date of Acceptance : 08/07/2020

Financial or other Competing Interests: None.

Date of Publication : 30/08/2020 